\title{
Analysis of pharmaceuticals in wastewater and removal using a membrane bioreactor
}

\author{
Jelena Radjenovic • Mira Petrovic • Damiá Barceló
}

Received: 6 July 2006/Revised: 22 September 2006 / Accepted: 25 September 2006/ Published online: 18 November 2006

(C) Springer-Verlag 2006

\begin{abstract}
Much attention has recently been devoted to the life and behaviour of pharmaceuticals in the water cycle. In this study the behaviour of several pharmaceutical products in different therapeutic categories (analgesics and antiinflammatory drugs, lipid regulators, antibiotics, etc.) was monitored during treatment of wastewater in a laboratoryscale membrane bioreactor (MBR). The results were compared with removal in a conventional activated-sludge (CAS) process in a wastewater-treatment facility. The performance of an MBR was monitored for approximately two months to investigate the long-term operational stability of the system and possible effects of solids retention time on the efficiency of removal of target compounds. Pharmaceuticals were, in general, removed to a greater extent by the MBR integrated system than during the CAS process. For most of the compounds investigated the performance of MBR treatment was better (removal rates $>80 \%$ ) and effluent concentrations of, e.g., diclofenac, ketoprofen, ranitidine, gemfibrozil, bezafibrate, pravastatin, and ofloxacin were steadier than for the conventional system. Occasionally removal efficiency was very similar, and high, for both treatments (e.g. for ibuprofen, naproxen, acetaminophen, paroxetine, and hydrochlorothiazide). The antiepileptic drug carbamazepine was the most persistent pharmaceutical and it passed through both the MBR and CAS systems untransformed. Because there was no washout of biomass from the reactor, high-quality effluent
\end{abstract}

J. Radjenovic · M. Petrovic · D. Barceló

Department of Environmental Chemistry, IIQAB-CSIC,

C/Jordi Girona 18-26,

08034 Barcelona, Spain

M. Petrovic $(\bowtie)$

Institucio Catalana de Reserca i Estudis Avanzats (ICREA),

08010 Barcelona, Spain

e-mail: mpeqam@cid.csic.es in terms of chemical oxygen demand (COD), ammonium content $\left(\mathrm{N}-\mathrm{NH}_{4}\right)$, total suspended solids (TSS), and total organic carbon (TOC) was obtained.

Keywords Wastewater treatment - Membrane bioreactor . Conventional activated sludge treatment . Pharmaceuticals . Removal efficiency

\section{Introduction}

Most pharmaceutical substances are, by nature, biologically active and hydrophilic, in order that the human body can take them up easily, and persistent, to avoid degradation before they have a curing effect. Depending on the pharmacology of a medical substance it will be excreted as a mixture of metabolites, as unchanged substance, or conjugated with an inactivating compound attached to the molecule [1]. When they enter a wastewater-treatment plant, xenobiotics are not usually completely mineralized. They are either partially retained in the sludge, or metabolized to a more hydrophilic but still persistent form and, therefore, pass through the wastewater-treatment plant (WWTP) and end up in the receiving waters. Their removal in WWTPs is variable and depends on the properties of the substance and process conditions (e.g. sludge retention time (SRT), hydraulic retention time (HRT), temperature) [2, 3]. Levels of many pharmaceutically active compounds (PhACs) are barely reduced and they are, therefore, detected in WWTP effluents. The presence of PhACs in surface, drinking, and wastewaters is well documented in the literature [1, 4-12]. Although present at low concentrations in the environment, drugs can have adverse effects on aquatic organisms. These effects are chronic rather than acutely toxic, and depend on exposure (bioavailability), 
susceptibility to the compound in question, and the degradability of the compound [13].

To ensure compliance with future discharge requirements, upgrading of existing wastewater-treatment facilities and implementation of new technologies is envisaged as the next step in improvement of wastewater treatment. In the last ten to fifteen years the use of membranes in wastewater reclamation has attracted much interest. Membrane technology has become a technically and economically feasible alternative for water and wastewater treatment, especially because of high SRTs achieved within compact reactor volumes. In the MBR the concentration of microorganisms can be increased to up to $20 \mathrm{mg} \mathrm{L}^{-1}$. Because of this high biomass concentration the rate of degradation is higher and specialists are grown for problematic compounds. Another advantage of membrane treatment is separation of suspended solids by membranes, so they are not limited by the settling characteristics of the sludge. The performance, in terms of effluent quality, is believed to be better, but there is a striking lack of knowledge about the behaviour of tracepollutants. Literature data on this subject is still very limited and contradictory [2, 11, 14-16]. Ultrafiltration membranes do not enable greater retention of the drugs investigated in this study as a result of filtration effects - the molecular sizes of the compounds selected are at least a factor of 100 smaller than the pore size of the membranes. Additional removal of hydrophobic compounds by membranes can, nevertheless, be expected, because they are adsorbed by particles deposited as a layer on the membrane surface; this effect for hydrophilic compounds is not yet very well defined, however [11, 17].

The objectives of this work were detection of target pharmaceuticals in wastewater influents and effluents, observation of their elimination in the CAS process, and comparison with results obtained for a laboratory-scale MBR provided with a plate-and-frame submerged membrane module. The pharmaceutical products investigated were analgesics and anti-inflammatory drugs (ibuprofen, ketoprofen, naproxen, diclofenac, indomethacin, acetaminophen, mefenamic acid, and propyphenazone), lipid regulators and cholesterol-lowering statin drugs (clofibric acid, gemfibrozil, bezafibrate, pravastatin, and mevastatin), antibiotics (erythromycin, azithromycin, sulfamethoxazole, trimethoprim, and ofloxacin), psychiatric drugs (fluoxetine and paroxetine), an antiepileptic drug (carbamazepine), $\beta$ blockers (atenolol, sotalol, metoprolol, and propranolol), anti-histaminics (famotidine and loratidine), anti-ulcer agents (lansoprazole and ranitidine), an anti-diabetic (glibenclamide), and a diuretic (hydrochlorothiazide). These compounds had different physicochemical properties (i.e. neutral, ionic, hydrophilic, hydrophobic). Their chemical structures and CAS numbers are listed in the Appendix. If their behaviour during wastewater treatment could be more reliably related to process design and operating conditions, process performance could possibly be improved by alteration of these conditions in accordance with the types of molecule that are difficult to eliminate.

\section{Experimental}

Materials and standards

Chemical standards of carbamazepine, lansoprazole, loratidine, famotidine, trimethoprim, ofloxacin, atenolol, metoprolol, azithromycin dihydrate, erythromycin hydrate, fluoxetine hydrochloride, ranitidine hydrochloride, sulfamethoxazole, propranolol hydrochloride, indomethacin, acetaminophen, mefenamic acid, clofibric acid, bezafibrate, mevastatin, and sotalol hydrochloride were purchased from Sigma-Aldrich (Steinheim, Germany), propyphenazone, pravastatin, and paroxetine hydrochloride from LGC Promochem (London, UK), ketoprofen, diclofenac, gemfibrozil, ibuprofen, and naproxen from Jescuder (Rubí, Spain), glibenclamide from SIFA Chemicals (Liestal, Switzerland), and hydrochlorothiazide from Pliva (Zagreb, Croatia). All pharmaceutical standards were of high-purity grade $(>90 \%)$.

Isotopically labelled compounds used as internal standards were ${ }^{13} \mathrm{C}$-Phenacetin, from Sigma-Aldrich, mecoprop- $\mathrm{d}_{3}$, from Dr Ehrenstorfer (Augsburg, Germany), and ibuprofen- $\mathrm{d}_{3}$, atenolol- $\mathrm{d}_{7}$, and carbamazepine- $\mathrm{d}_{10}$ from CDN Isotopes (Quebec, Canada).

All solvents (methanol, acetonitrile, and water) were HPLC-grade and were purchased from Merck (Darmstadt, Germany), as also was hydrochloric acid ( $\mathrm{HCl}, 37 \%)$, ammonium acetate $\left(\mathrm{NH}_{4} \mathrm{Ac}\right)$, and acetic acid (HAc). Nitrogen for drying, purity $99.995 \%$, was from Air Liquide (Spain).

Stock solutions of individual standards $\left(1 \mathrm{~g} \mathrm{~L}^{-1}\right)$ and internal standards were prepared in methanol and stored at $-20{ }^{\circ} \mathrm{C}$. Stock solutions of ofloxacin, pravastatin, and sulfamethoxazole were renewed monthly because of their limited stability. A standard mixture in which the compounds were at a concentration of approx. $20 \mathrm{mg} \mathrm{L}^{-1}$ was prepared from the stock solutions. Further dilutions of this mixture were prepared in 25:75 (v/v) methanol-water and were used as working standard solutions. A mixture of internal standards prepared by dilution of individual stock solutions in methanol was used for internal standard calibration.

Membrane bioreactor (MBR)

A submerged MBR of approximately $21 \mathrm{~L}$ active volume equipped with two flat sheet membranes (A4 size, area $0.106 \mathrm{~m}^{2}$, pore size $0.4 \mu \mathrm{m}$ ), purchased from Kubota 
(Osaka, Japan), was installed in a municipal WWTP in Rubí (Barcelona, Spain). Although the nominal porosity of the membranes was $0.4 \mu \mathrm{m}$ (microfiltration) a fouling layer of proteins and microorganisms formed on the surface of the membranes reduced the effective porosity to $0.01 \mu \mathrm{m}$, which brought the type of filtration into the ultrafiltration range [17].

The MBR was operated in parallel with the CAS process (aeration tank and secondary settling tank). The biocenosis of the MBR was grown from inoculated sludge from the municipal WWTP (aeration basin) and cultivated over a period of approximately 1 month to reach steady-state conditions. The hydraulic retention time was set to $14 \mathrm{~h}$ by regulating the effluent flow and the SRT was infinite, because no sludge was discharged from the reactor.

The laboratory-scale MBR was operated dynamically in intermittent permeation mode-cycles of permeation for 8 min interrupted with 2 min of halt. Influent and permeate flows were controlled by use of flow meters and computercontrolled pumps. Continuous aeration was provided by means of a sparger pipe situated at the bottom of the reaction vessel; the oxygen concentration was kept between 1 and $2 \mathrm{mg} \mathrm{L}^{-1}$. The temperature inside the reactor was $20 \pm 2{ }^{\circ} \mathrm{C}$ throughout sampling.

\section{Wastewater-treatment plant (WWTP)}

Rubí WWTP was designed for 125,550 inhabitant equivalents. During the sampling programme the WWTP was operating with an average daily flow of $22,000 \mathrm{~m}^{3}$ day $^{-1}$. A mixture of municipal, hospital, and industrial wastewater is treated. Treatment consists of pretreatment, preliminary treatment, primary sedimentation, and secondary (biological) treatment. Pretreated wastewater goes through a physical process of settling in a primary clarifier. Secondary treatment occurs in pre-denitrification (anaerobic) and nitrification (aerobic) tanks, and two secondary clarifiers. Secondary sludge is recirculated to a primary clarifier which improves the settling characteristics of the primary sludge and increases sludge age. A mixture of primary and secondary (activated) sludge is processed (thickening, dewatering) and anaerobically digested, and biogas produced is used to heat a digester. The hydraulic retention time of CAS treatment in WWTP Rubí, calculated for the average daily flow, is approximately $12 \mathrm{~h}$. During the sampling programme the plant was operating with an SRT of approximately 3 days. WWTP effluent is discharged into the river Riera de Rubí, which flows into the Mediterranean sea.

Sampling and sample preparation

Sampling was conducted during May and June, 2005. Twenty-eight samples were analyzed. All wastewater samples were taken as time-proportional grab-samples, bearing in mind the HRT of the MBR and CAS processes. The sampling points were:

1. primary sedimentation tank effluent, as the inflow to the conventional treatment plant and membrane bioreactor,

2. CAS effluent, and

3. MBR effluent.

Wastewater samples were collected, in amber glass bottles pre-rinsed with ultra-pure water, as 24-h composite samples; the volume depended on the type of sample (100 mL for influent wastewater and $200 \mathrm{~mL}$ for effluent). Immediately on arrival at the laboratory they were filtered through $1-\mu \mathrm{m}$ glass fibre filters and then through $0.45 \mu \mathrm{m}$ Nylon membrane filters from Whatman (UK). The target compounds were extracted in one step, by a method described elsewhere [18], using a Baker vacuum system (J.T. Baker, The Netherlands) and Waters (Milford, MA, USA) Oasis HLB cartridges $(60 \mathrm{mg}, 3 \mathrm{~mL})$ previously conditioned at neutral $\mathrm{pH}$ with $5 \mathrm{~mL}$ methanol then $5 \mathrm{~mL}$

Table 1 MRM transitions of the compounds analyzed

\begin{tabular}{|c|c|c|c|}
\hline Compound & MRM 1 & MRM 2 & MRM 3 \\
\hline Ibuprofen & $205 \rightarrow 161$ & & \\
\hline Ketoprofen & $253 \rightarrow 209$ & $253 \rightarrow 197$ & \\
\hline Naproxen & $229 \rightarrow 170$ & $229 \rightarrow 185$ & \\
\hline Diclofenac & $294 \rightarrow 250$ & $294 \rightarrow 214$ & \\
\hline Indomethacin & $356 \longrightarrow 297$ & $356 \rightarrow 255$ & \\
\hline Acetaminophen & $152 \rightarrow 110$ & $152 \rightarrow 93$ & \\
\hline Mefenamic acid & $240 \rightarrow 196$ & $240 \rightarrow 180$ & \\
\hline Propyphenazone & $231 \rightarrow 201$ & $231 \rightarrow 189$ & \\
\hline Clofibric acid & $213 \rightarrow 127$ & $213 \rightarrow 85$ & \\
\hline Gemfibrozil & $249 \rightarrow 121$ & & \\
\hline Bezafibrate & $360 \rightarrow 274$ & $360 \rightarrow 154$ & \\
\hline Pravastatin & $447 \rightarrow 327$ & & \\
\hline Mevastatin & $391 \rightarrow 185$ & $391 \rightarrow 159$ & \\
\hline Carbamazepine & $237 \rightarrow 194$ & $237 \rightarrow 192$ & \\
\hline Fluoxetine & $310 \rightarrow 44$ & $310 \rightarrow 148$ & \\
\hline Paroxetine & $330 \rightarrow 192$ & $330 \rightarrow 123$ & \\
\hline Lansoprazole & $370 \rightarrow 252$ & $370 \rightarrow 205$ & \\
\hline Famotidine & $338 \rightarrow 189$ & $338 \rightarrow 259$ & \\
\hline Ranitidine & $315 \rightarrow 176$ & $315 \rightarrow 130$ & \\
\hline Loratidine & $383 \rightarrow 337$ & $383 \rightarrow 267$ & $383 \rightarrow 259$ \\
\hline Erythromycin & $734.5 \rightarrow 158$ & $734.5 \rightarrow 576.4$ & \\
\hline Azithromycin & $749.5 \rightarrow 591.4$ & $749.5 \rightarrow 158$ & \\
\hline Sulfamethoxazole & $254 \rightarrow 92$ & $254 \rightarrow 156$ & \\
\hline Trimethoprim & $291 \rightarrow 230$ & $291 \rightarrow 261$ & \\
\hline Ofloxacin & $362 \rightarrow 316$ & & \\
\hline Atenolol & $267 \rightarrow 190$ & $267 \rightarrow 145$ & \\
\hline Sotalol & $273 \rightarrow 255$ & $273 \rightarrow 213$ & \\
\hline Metoprolol & $268 \rightarrow 133$ & $268 \rightarrow 159$ & \\
\hline Propranolol & $260 \rightarrow 166$ & $260 \rightarrow 183$ & \\
\hline Hydrochlorothiazide & $296 \rightarrow 269$ & $296 \rightarrow 205$ & \\
\hline Glibenclamide & $494 \rightarrow 369$ & & \\
\hline
\end{tabular}


deionised water (HPLC grade). Elution was performed twice with $4 \mathrm{~mL}$ methanol at a flow of $1 \mathrm{~mL} \mathrm{~min}^{-1}$. The extracts were then evaporated under a nitrogen stream and reconstituted with $1 \mathrm{~mL}$ 25:75 (v/v) methanol-water.

Chemical analysis

LC analysis was performed with a Waters (Milford, MA, USA) 2690 HPLC system coupled to a Micromass Quattro (Manchester, UK) triple quadrupole mass spectrometer equipped with a Z-spray electrospray interface. Chromatographic separation was achieved on a Purospher Star RP-18 endcapped column $(125 \mathrm{~mm} \times 2.0 \mathrm{~mm}$, particle size $5 \mu \mathrm{m})$ and a $\mathrm{C}_{18}$ guard column, both from Merck.

A specific multi-residue analytical method was set up for measurement of the concentrations of the pharmaceutical compounds in wastewaters [18]. Analysis was performed in multiple-reaction-monitoring (MRM) mode, in both posi- tive and negative electrospray-ionization mode. This method was refined for analysis of hydrochlorothiazide and glibenclamide. MRM transitions selected for each compound are summarized in Table 1. In accordance with the performance characteristics defined in EU Commission Decision 2002/657/EC for confirmation and identification of pharmaceuticals when using LC-tandem MS as the instrumental technique, a minimum of three identification points are required. When using LC-MS-MS (QqQ) analysis two MRM transitions are sufficient to confirm the identity of a compound. The MRM ratio, calculated as the relationship between the abundances of both transitions and the LC retention time are also criteria used to confirm the presence of an analyte in the samples. In this study, therefore, transitions between a precursor ion and the two most abundant fragment ions were chosen for each analyte when working in MRM mode, resulting in four identification points, enough to conform with the aforementioned EU

Table 2 Mean recoveries of the selected compounds and method detection limits (MDL) in $n g \mathrm{~L}^{-1}$

\begin{tabular}{|c|c|c|c|c|c|}
\hline \multirow[t]{2}{*}{ Compound } & \multicolumn{3}{|l|}{ Recovery (\%) } & \multicolumn{2}{|c|}{ MDL (ng L $\left.{ }^{-1}\right)$} \\
\hline & Influent & MBR effluent & CAS effluent & Influent & MBR and CAS effluent \\
\hline Ibuprofen & $131(18.1)^{\mathrm{a}}$ & $68.8(11.0)$ & $90.4(11.0)$ & 98.0 & 20.0 \\
\hline Ketoprofen & $62.8(2.94)$ & $71.3(3.11)$ & $59.1(0.897)$ & 190 & 74.0 \\
\hline Naproxen & $49.2(20.0)$ & $59.4(1.28)$ & $53.4(2.31)$ & 79.0 & 20.0 \\
\hline Diclofenac & $83.3(1.17)$ & $94.9(10.0)$ & $95.0(12.6)$ & 160 & 40.0 \\
\hline Indomethacin & $113(2.95)$ & $120(5.63)$ & $110(3.78)$ & 150 & 31.0 \\
\hline Acetaminophen & $123(17.0)$ & $108(10.5)$ & $56.0(7.61)$ & 20.9 & 5.35 \\
\hline Mefenamic acid & $93.3(1.95)$ & $92.1(1.02)$ & $91.5(5.29)$ & 5.70 & 1.85 \\
\hline Propyphenazone & $60.0(8.00)$ & $71.0(4.00)$ & $71.0(4.00)$ & 4.80 & 1.45 \\
\hline Clofibric acid & $86.0(10.8)$ & $104(6.87)$ & $74.5(1.40)$ & 16.3 & 3.75 \\
\hline Gemfibrozil & $91.0(8.47)$ & $87.5(1.36)$ & $108(17.2)$ & 8.70 & 2.20 \\
\hline Bezafibrate & $106(3.43)$ & $94.4(9.30)$ & $89.4(4.62)$ & 18.5 & 4.35 \\
\hline Pravastatin & $85.6(2.56)$ & $78.0(12.2)$ & $96.0(19.5)$ & 120 & 30.9 \\
\hline Mevastatin & $103(8.61)$ & $134(15.6)$ & $123(9.86)$ & 9.30 & 1.30 \\
\hline Carbamazepine & $84.0(7.84)$ & $89.5(5.20)$ & $88.0(9.24)$ & 2.20 & 0.600 \\
\hline Fluoxetine & $46.7(2.34)$ & $93.7(17.6)$ & $59.0(1.60)$ & 19.8 & 1.70 \\
\hline Paroxetine & $62.2(2.15)$ & $109(5.73)$ & $71.4(1.49)$ & 3.50 & 0.650 \\
\hline Lansoprazole & $70.0(10.0)$ & $87.0(5.00)$ & $86.0(4.00)$ & 10.9 & 4.20 \\
\hline Famotidine & $58.2(7.76)$ & $55.4(6.30)$ & $66.6(5.39)$ & 3.10 & 0.40 \\
\hline Ranitidine & $41.5(9.85)$ & $75.8(14.8)$ & $125(11.7)$ & 1.40 & 0.300 \\
\hline Loratidine & $72.6(1.81)$ & $78.0(6.97)$ & $64.5(4.98)$ & 8.00 & 2.75 \\
\hline Erythromycin & $67.7(3.15)$ & $50.0(13.0)$ & $66.6(12.0)$ & 12.4 & 2.00 \\
\hline Azithromycin & $30.0(7.00)$ & $73.0(2.00)$ & $63.0(3.00)$ & 1.00 & 0.300 \\
\hline Sulfamethoxazole & $33.7(2.76)$ & $95.5(9.24)$ & $78.3(1.08)$ & 16.1 & 3.10 \\
\hline Trimethoprim & $58.8(3.29)$ & $128(6.58)$ & $60.8(3.87)$ & 1.30 & 0.350 \\
\hline Ofloxacin & $142(19.0)$ & $135(5.45)$ & $138(4.47)$ & 29.3 & 7.85 \\
\hline Atenolol & $83.5(33.8)$ & $60.8(10.8)$ & $131(15.5)$ & 1.70 & 0.750 \\
\hline Sotalol & $47.1(2.91)$ & $31.9(3.05)$ & $52.0(3.63)$ & 4.80 & 0.700 \\
\hline Metoprolol & $36.7(1.44)$ & $120(2.64)$ & $76.7(1.43)$ & 6.30 & 1.60 \\
\hline Propranolol & $60.2(0.506)$ & $90.8(4.02)$ & $70.5(5.27)$ & 2.60 & 0.300 \\
\hline Hydrochlorothiazide & 39.8 (7.43) & $58.9(1.62)$ & $73.4(22.9)$ & 4.50 & 0.900 \\
\hline Glibenclamide & $100(11.7)$ & $107(10.3)$ & $98.5(11.7)$ & 19.2 & 2.30 \\
\hline
\end{tabular}

${ }^{\mathrm{a}}$ The relative standard deviation $(\%)$ of the recoveries is given in parentheses $(n=3)$ 
directive. When poor fragmentation was observed for the compounds, only one transition could be monitored. Confirmation of the identities of these was achieved by matching their LC retention times with those of standards. Shifts in retention times were less than $3 \%$, so the confirmation was regarded as sufficiently reliable. For internal standards only one transition was selected, because they were isotopically labelled compounds unlikely to be found in environmental samples.

To compensate for matrix effects from sample matrices internal standard calibration and adequate dilution of sample extracts were used, on the basis of the previously published method [18].

Recoveries of the method were determined by spiking. Influent samples and CAS and MBR effluents were spiked in triplicate with a standard mixture of selected compounds to a final concentration of $1 \mu \mathrm{g} \mathrm{L}{ }^{-1}$. Spiked samples and a blank sample were analysed by the above mentioned method. Recoveries of the target pharmaceuticals are listed in Table 2, with method detection limits (MDL) for influent and effluent samples. MDLs and method quantification limits (MQL) were calculated on the basis of signal-tonoise ratios $(S / N)$ of 3 and 10 , respectively.

\section{Results and discussion}

It is well documented that WWTPs are major contributors of pharmaceuticals in the environment. WWTP Rubí mainly receives domestic, hospital, and industrial wastewater and effluent concentrations of several monitored compounds exceed $\mu \mathrm{g} \mathrm{L}^{-1}$ levels. Ranges of output loads for WWTP Rubi for each pharmaceutical and mean values $\left(\mathrm{g} \mathrm{day}^{-1}\right.$ ) are reported in Table 3 . The quantities of pharmaceuticals discharged into the environment are calculated by multiplying the detected effluent concentrations by an average daily flow rate of $22,000 \mathrm{~m}^{3}$ day $^{-1}$. The total amount of pharmaceutical compounds discharged by WWTP Rubi into the environment exceeded $300 \mathrm{~g}^{\text {day }}{ }^{-1}$ (an average value). The most abundant compounds, with average individual loads of 21-56 $\mathrm{g} \mathrm{day}^{-1}$, were the antiinflammatory drugs ibuprofen, naproxen, and diclofenac, the lipid regulators gemfibrozil and bezafibrate, the diuretic hydrochlorothiazide, and the $\beta$-blocker atenolol.

To assess the efficiency of elimination by the MBR, substance-specific analysis must be performed and the bulk properties DOC and COD of wastewater influents and effluents must also be determined. The performance of the MBR system is summarized in Table 4. The data are presented for the sampling period. Removal efficiencies of $98.7 \%$ for TSS and $90.4 \%$ for total COD were achieved during the membrane process. Average effluent ammonia concentration was $1.01 \mu \mathrm{g} \mathrm{L}^{-1}$ in the MBR effluent, com-
Table 3 Average daily output loads of the investigated pharmaceuticals for Rubí WWTP

\begin{tabular}{|c|c|c|}
\hline \multirow[t]{2}{*}{ Pharmaceutical } & \multicolumn{2}{|c|}{ Effluent load $\left(\mathrm{g} \mathrm{day}^{-1}\right)$} \\
\hline & Mean & Range \\
\hline \multicolumn{3}{|c|}{ Analgesics and anti-inflammatory drugs } \\
\hline Naproxen & 37.0 & $10.8-76.9$ \\
\hline Ketoprofen & 17.1 & $11.4-36.3$ \\
\hline Ibuprofen & 56.3 & $7.39-137.9$ \\
\hline Diclofenac & 27.3 & $17.3-43.8$ \\
\hline Indomethacin & 1.93 & nd-2.73 \\
\hline Acetaminophen & 4.55 & $1.06-9.2$ \\
\hline Mefenamic acid & 0.44 & $0.27-0.85$ \\
\hline Propyphenazone & 0.68 & $0.43-0.96$ \\
\hline \multicolumn{3}{|l|}{ Anti-ulcer agent } \\
\hline Ranitidine & 2.77 & $0.55-5.30$ \\
\hline \multicolumn{3}{|l|}{ Psychiatric drug } \\
\hline Paroxetine & 0.08 & $\mathrm{nd}^{\mathrm{a}}-0.16$ \\
\hline \multicolumn{3}{|l|}{ Antiepileptic drug } \\
\hline Carbamazepine & 5.21 & $1.44-6.71$ \\
\hline \multicolumn{3}{|l|}{ Antibiotics } \\
\hline Ofloxacin & 6.93 & $2.40-11.2$ \\
\hline Sulfamethoxazole & 3.06 & $1.42-5.81$ \\
\hline Erythromycin & 2.29 & $0.95-4.51$ \\
\hline \multicolumn{3}{|l|}{$\beta$-blockers } \\
\hline Atenolol & 21.0 & $7.70-33.2$ \\
\hline Metoprolol & 3.32 & $1.14-5.43$ \\
\hline \multicolumn{3}{|l|}{ Diuretic } \\
\hline Hydrochlorothiazide & 33.7 & $21.2-46.0$ \\
\hline \multicolumn{3}{|l|}{ Hypoglycaemic agent } \\
\hline Glibenclamide & 0.74 & nd -0.98 \\
\hline \multicolumn{3}{|c|}{ Lipid regulator and cholesterol lowering statin drugs } \\
\hline Gemfibrozil & 54.3 & $30.1-73.9$ \\
\hline Bezafibrate & 21.6 & $10.9-50.8$ \\
\hline Clofibric acid & 1.75 & $0.40-3.43$ \\
\hline Pravastatin & nd & nd \\
\hline
\end{tabular}

${ }^{a}$ Not detectable (below the LOQ)

pared with $48.41 \mu \mathrm{g} \mathrm{L} \mathrm{L}^{-1}$ in the CAS effluent. It is known that membrane processes are quite efficient at removing COD and TOC from wastewater [19, 20]. Improved COD removal is attributed to the combination of complete retention of particulate material by the membrane, including suspended COD and high molecular weight organisms, and to avoidance of biomass washout problems common in activated sludge systems. Consequently, stable conditions are provided for growth of specialized microorganisms which are the able to remove poorly biodegradable components.

Of 31 pharmaceutical products included in the analytical method, 22 were detected in the wastewater entering WWTP Rubí. Box plots of measured concentrations of each pharmaceutical are showed in Figs. 1, 2 and 3. Ten measured values are given for influent and MBR effluent concentrations and eight for CAS effluent (data are missing 
Table 4 Summary of the performance of the MBR system

${ }^{a}$ Values are averages from $n=16$ samples, with standard deviations in parentheses

\begin{tabular}{llll}
\hline Property & Influent & MBR effluent & CAS effluent \\
\hline $\mathrm{TSS}\left(\mathrm{mg} \mathrm{L}^{-1}\right)$ & $119.2(17.37)^{\mathrm{a}}$ & $1.600(1.770)$ & $26.72(15.69)$ \\
$\mathrm{COD}_{\text {total }}\left(\mathrm{mg} \mathrm{L}^{-1}\right)$ & $508.2(124.3)$ & $48.58(22.47)$ & $111.6(53.35)$ \\
${\mathrm{TOC}\left(\mathrm{mg} \mathrm{L}^{-1}\right)}_{\mathrm{N}-\mathrm{NH}_{4}\left(\mathrm{mg} \mathrm{L}^{-1}\right)}^{67.67(24.29)}$ & $10.89(3.470)$ & $27.33(13.75)$ \\
$\mathrm{pH}$ & $49.13(15.79)$ & $1.010(0.4200)$ & $48.41(12.87)$ \\
\hline
\end{tabular}

for two sampling programmes). For each variable the box has lines at the lower quartile $(25 \%)$, median $(50 \%)$, and upper quartile $(75 \%)$ values. The whiskers are the lines extending from each end of the box to show the extent of the data up to 1.5 times the interquartile range (IQR). Outliers are marked with + symbols.

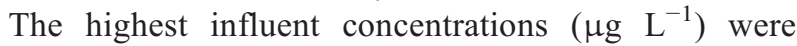
measured for the analgesics and anti-inflammatory drugs naproxen, ibuprofen, ketoprofen, diclofenac, and acetaminophen, the antihyperlipoproteinaemic drugs gemfibrozil and bezafibrate, the $\beta$-blocker atenolol, and the diuretic hydrochlorothiazide. For other compounds input concentrations were usually in the range $10-100 \mathrm{ng} \mathrm{L}^{-1}$. Because the low concentrations measured were sometimes close to the limits of quantification, any hypothesis about the efficiency of their elimination is questionable. Mean removal was, nevertheless, calculated for each of the pharmaceutical compounds; the results are presented in Table 5. The most important removal pathways of organic compounds during wastewater treatment are:

1. biotransformation/biodegradation,

2. adsorption by the sludge (excess sludge removal), and

3. stripping by aeration (volatilization).

Because of the low values of the Henry coefficients $\left(K_{\mathrm{H}}\right)$ of the compounds investigated [21], the fraction removed by volatilization can be neglected [16]. The two processes abiotic (adsorption) and biotic degradation (transformation by microorganisms) could not be distinguished, because no method was developed for analysis of the target compounds in sludge. The term "removal" is therefore used here for conversion of a micropollutant to compounds other than the parent compound.

Elimination efficiency of the laboratory-scale MBR and the full-scale CAS process was comparable for naproxen, ibuprofen, acetaminophen, hydrochlorothiazide, and paroxetine. All were removed to a large extent by both systems (removal was greater than $80 \%$ except for hydrochlorothiazide, for which it was between 56 and 85\%). Hydrochlorothiazide and paroxetine were eliminated slightly better by conventional treatment. Similar results for the behaviour of these drugs during conventional treatment have been reported by several authors $[2,3,9,11]$.
For ketoprofen, diclofenac, bezafibrate, and gemfibrozil removal by the MBR system was very high and uniform $(>90 \%)$, with the exception of two sampling programme. It is assumed this variation could have been a result of reduced microbial activity or altered sorption and flocculation conditions. No plausible explanation can be given for the drastically reduced efficiency of removal of clofibric and mefenamic acid by MBR in two sampling programmes; otherwise these were eliminated with efficiencies between 65 and $90 \%$. High and steady removal (>80\%) in the MBR was also observed for ranitidine and ofloxacin. In conventional treatment all these pharmaceuticals were eliminated with a wide range of efficiencies, always lower than those obtained by the MBR. Better removal of readily biodegradable micropollutants by the MBR could be because of the smaller flock size of the sludge, which enhances mass transfer by diffusion and therefore increases elimination. Taking into consideration the composition of sludge originating from a membrane bioreactor (specialized microorganisms, large amount of active biomass in suspended solids) improved removal is to be expected; this was confirmed by our experiments.

A possible explanation of substantially greater attenuation of diclofenac by the MBR (average removal efficiency $87 \%$ compared with $50 \%$ in CAS) could be the greater age of the MBR sludge. Improved removal is observed with increasing solids retention time [14]. Another explanation could be greater adsorption potential of the MBR sludge, because the organic matter content is greater than for CAS sludge. According to results from the EU project Poseidon [22], adsorption processes affect elimination of diclofenac. Literature data on this matter is still very contradictory. Clara et al. reported poor removal of diclofenac in laboratory-scale WWTPs whereas in full-scale plants removal varied from less than $20 \%$ to between 60 and $80 \%$ for some of the facilities investigated [2]. Heberer et al. [7] reported low removal efficiencies in a WWTP whereas Ternes et al. documented significant (69\%) elimination of diclofenac [8].

Removal of carbamazepine was, in contrast, very poor $(<20 \%)$, and effluent concentrations for both MBR and CAS were frequently greater than influent levels. Poor elimination of this neutral drug has been reported by many authors [9, 11, 23, 24]. Glucuronide conjugates of carba- 

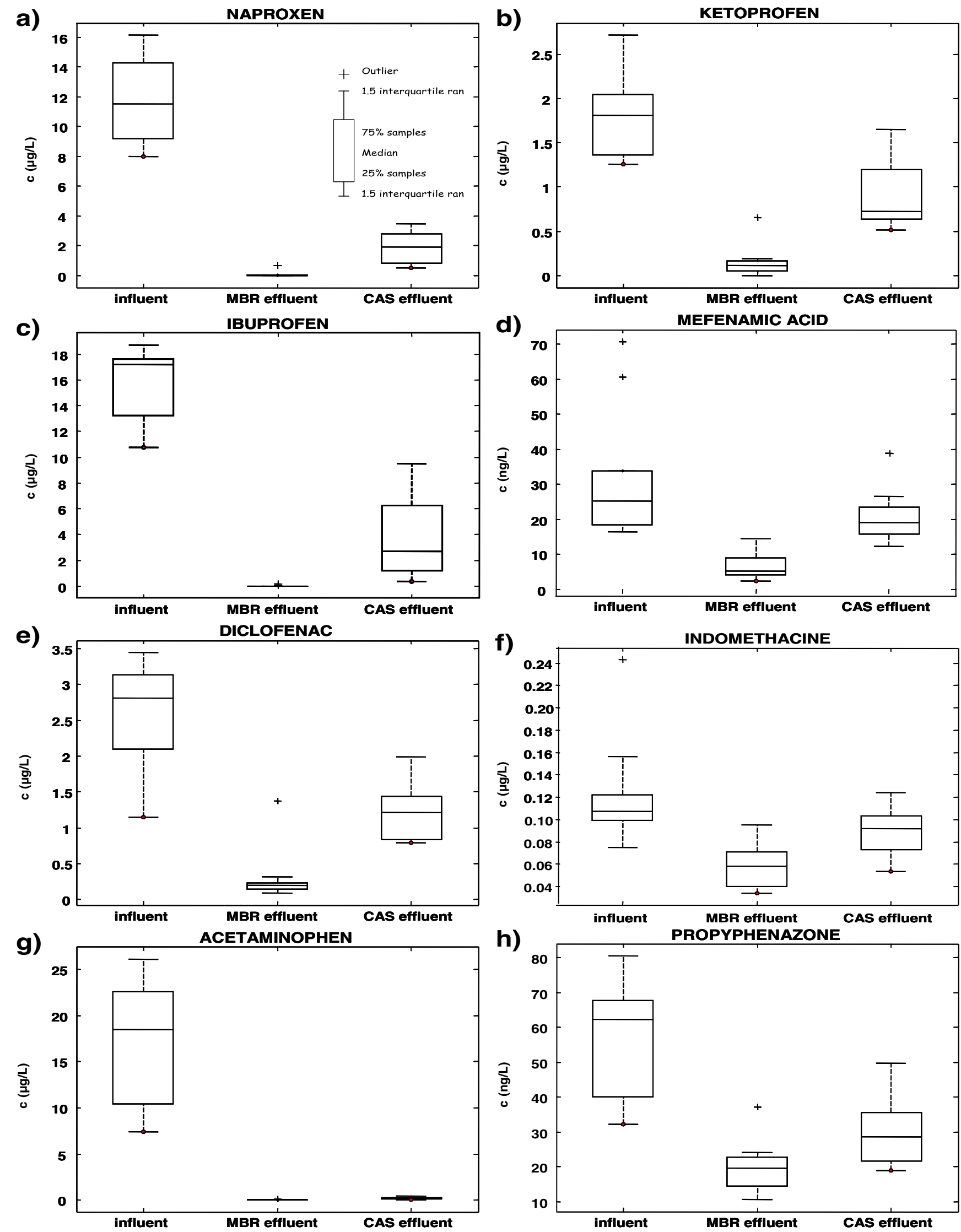

Fig. 1 Removal, during MBR and CAS treatment, of the analgesics and anti-inflammatory drugs naproxen (a), ketoprofen (b), ibuprofen (c), mefenamic acid (d), diclofenac (e), indomethacin (f), acetaminophen (g), and propyphenazone (h) 
a)
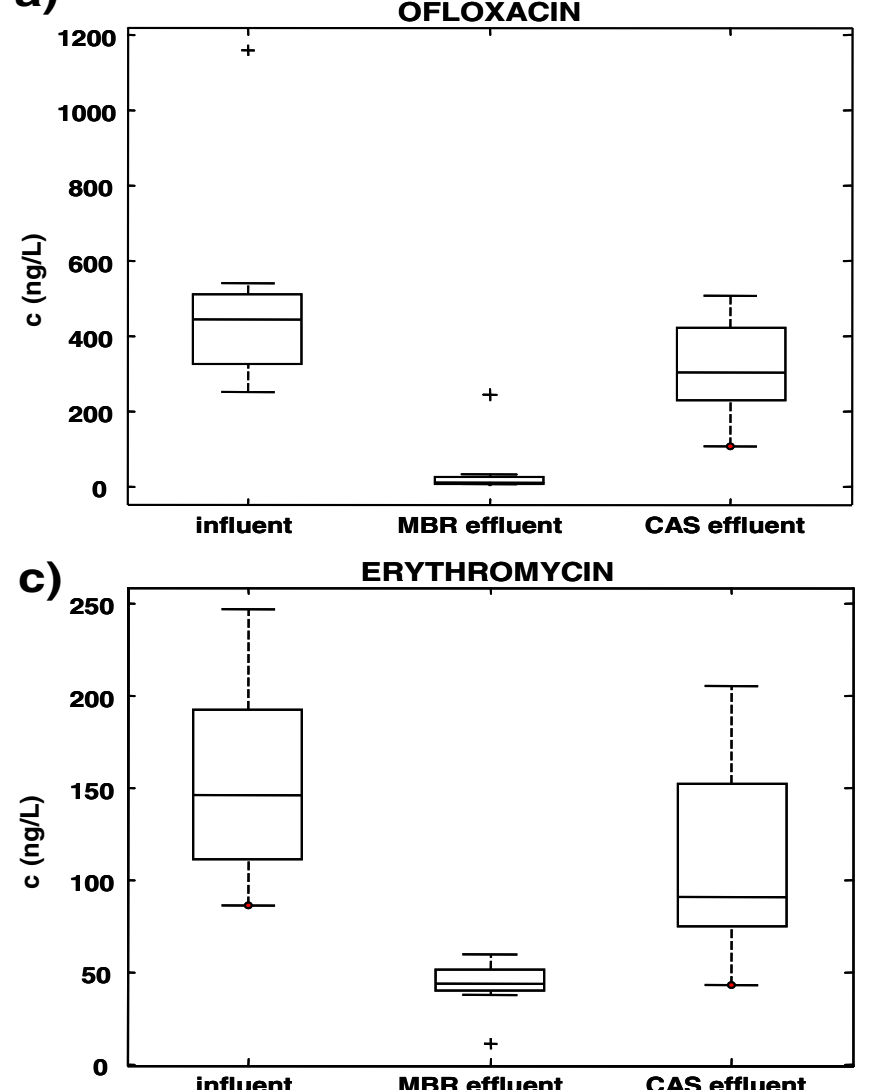

e)
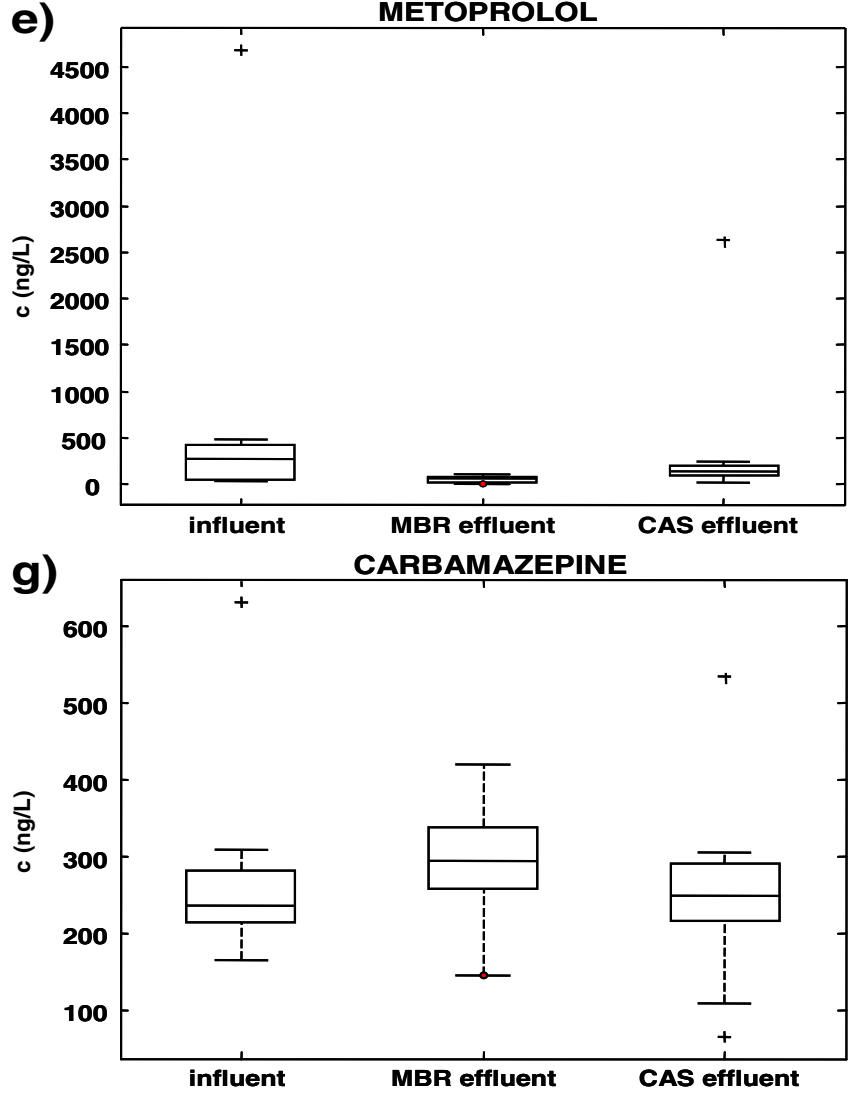

b)

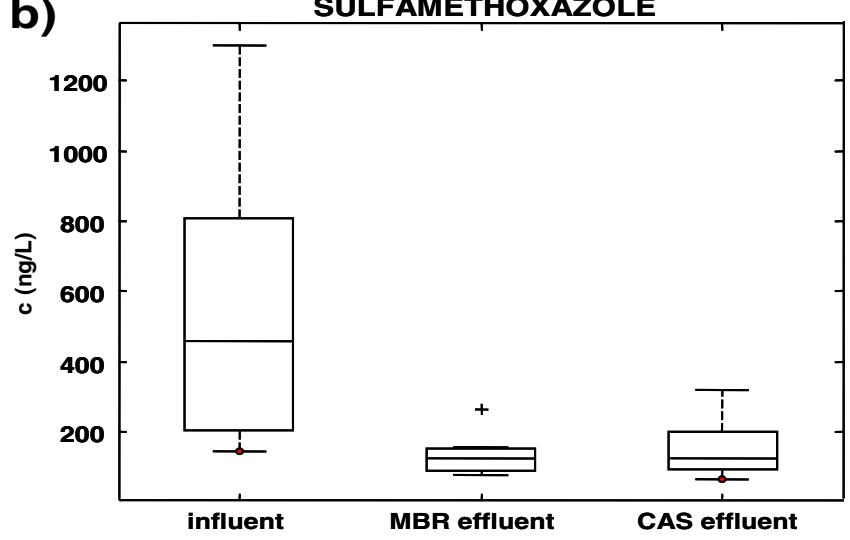

d)
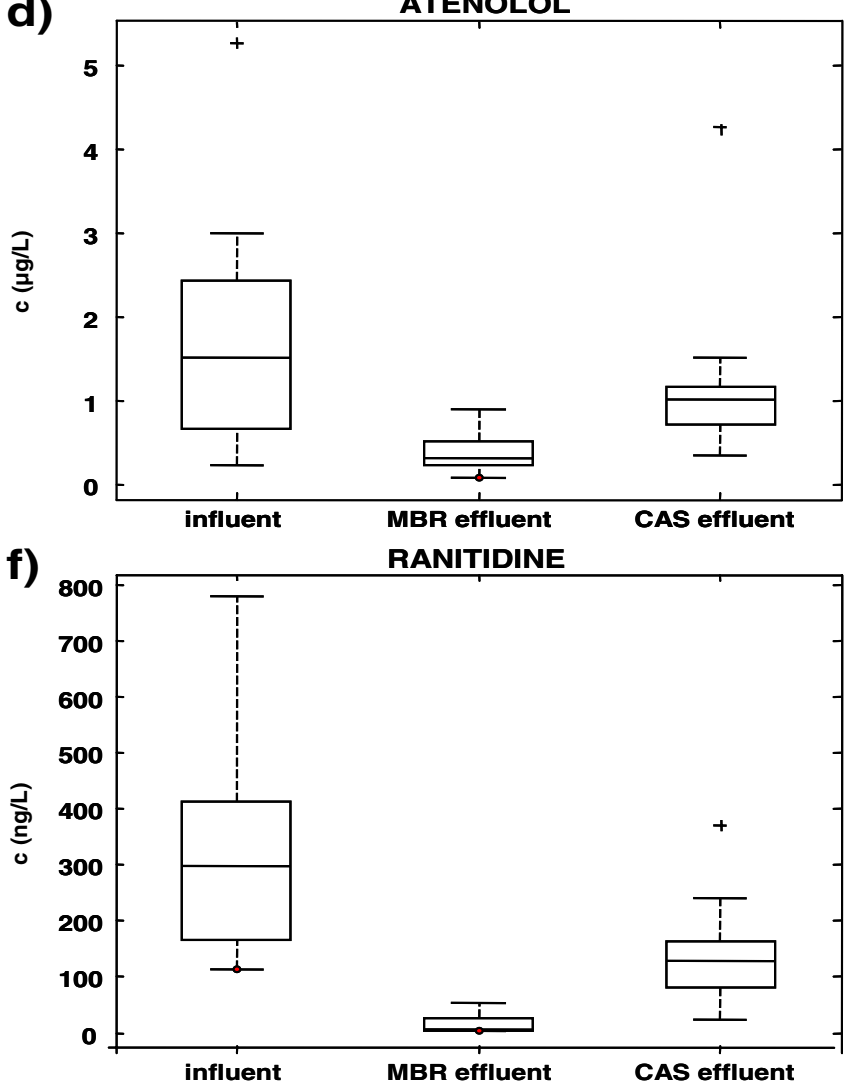

h)

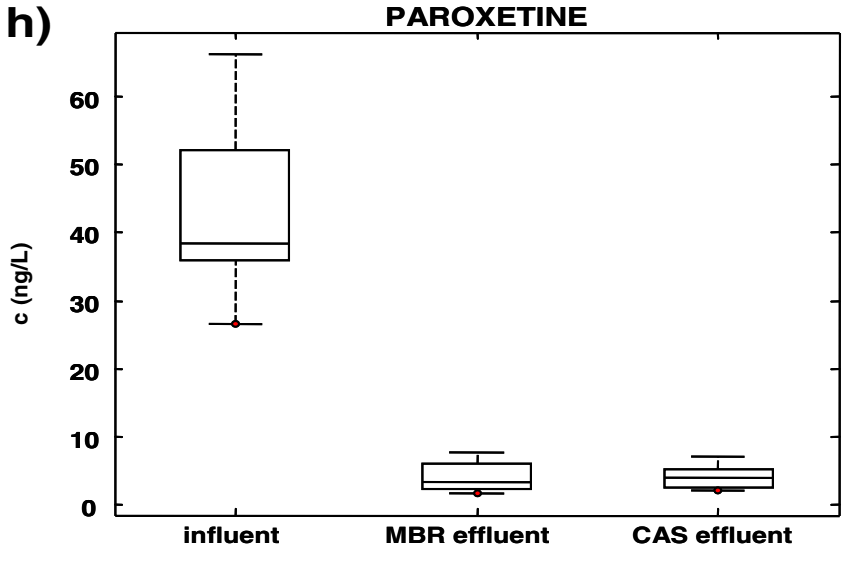


Fig. 2 Removal during MBR and CAS treatment of the antibiotics ofloxacin (a), sulfamethoxazole (b), and erythromycin (c), the $\beta$ blockers atenolol (d) and metoprolol (e), the anti-ulcer agent ranitidine (f), the antiepileptic drug carbamazepine (g), and the psychiatric drug paroxetine (h)

mazepine can, presumably, be cleaved in sewage, thus increasing environmental concentrations [8].

Rates of removal of the antibiotic sulfamethoxazole were very variable in both treatments investigated. According to Drillia et al. its microbial degradation will depend on the

a)

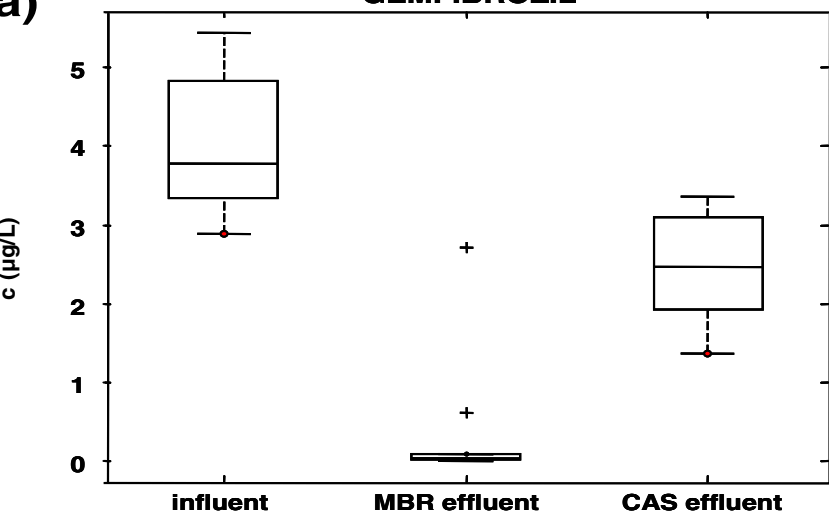

c)

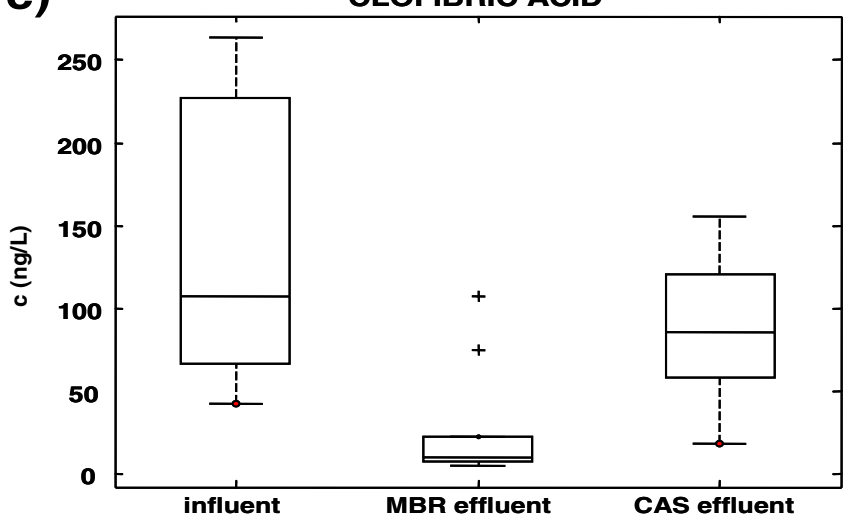

e)

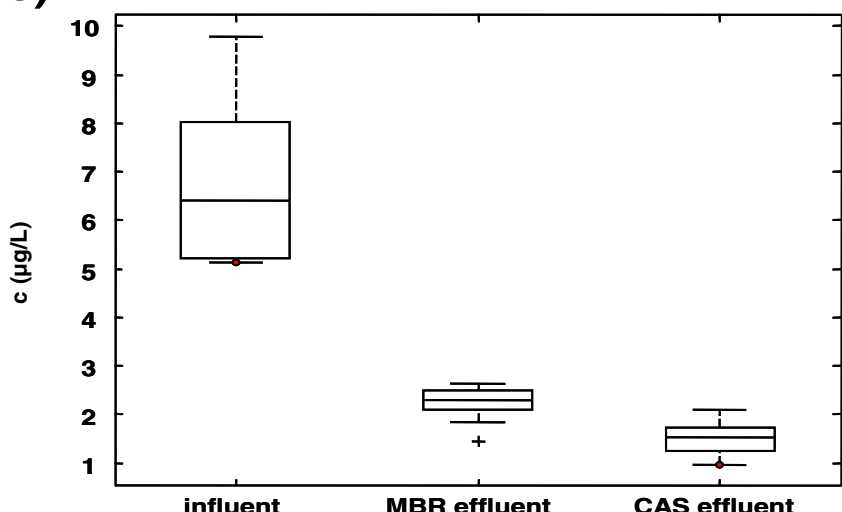

presence of readily biodegradable organic matter in wastewater; this varies during both MBR and CAS treatment [25]. Also, a substantial amount of sulfamethoxazole enters WWTPs as its human metabolite $N_{4}$-acetylsulfamethoxazole, which can possibly be converted back to the original compound during treatment [26].

Efficiency of removal of atenolol, metoprolol, pravastatin, erythromycin, and indomethacin varied in both MBR and CAS treatment. This could not be explained. Fluctuation of elimination efficiency was also observed for propyphenazone b)

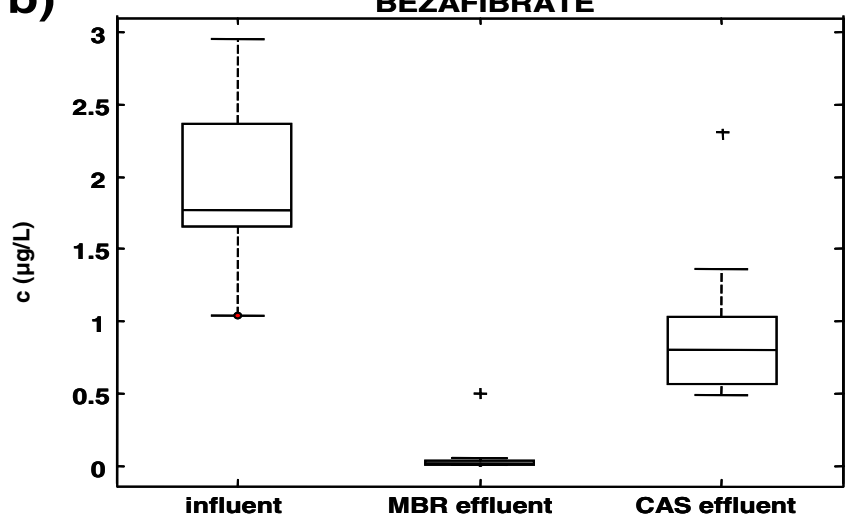

d)

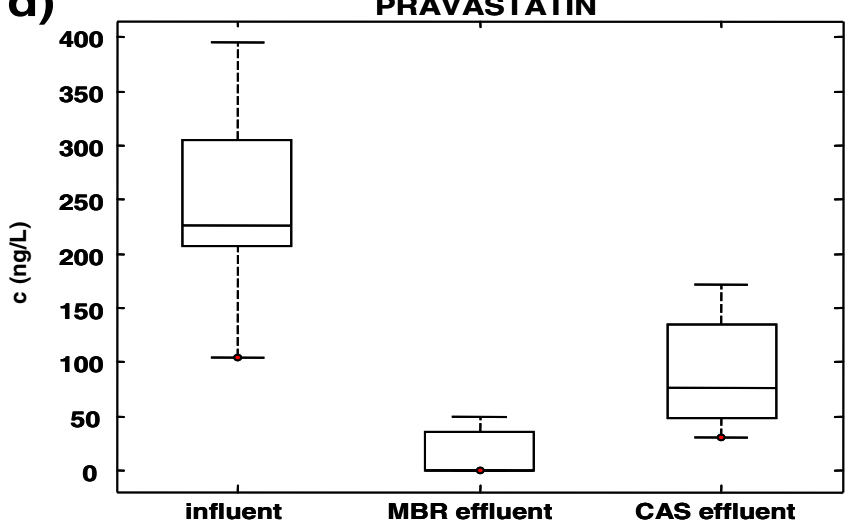

f)

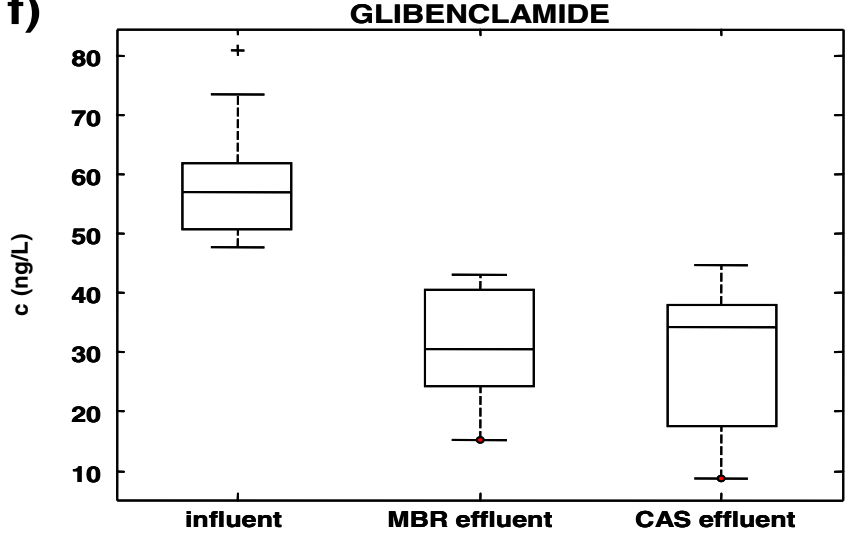

Fig. 3 Removal during MBR and CAS treatment of the lipid regulator and cholesterol-lowering statin drugs gemfibrozil (a), bezafibrate (b), clofibric acid (c), and pravastatin (d), the diuretic hydrochlorothiazide (e), and the hypoglycaemic agent glibenclamide (f) 
Table 5 Mean removal of selected pharmaceuticals by the MBR and CAS processes

\begin{tabular}{|c|c|c|}
\hline \multirow[t]{2}{*}{ Compound } & \multicolumn{2}{|c|}{ Elimination (\%) in: } \\
\hline & $\mathrm{MBR}^{\mathrm{a}}$ & $\mathrm{CAS}^{\mathrm{b}}$ \\
\hline \multicolumn{3}{|c|}{ Analgesics and anti-inflammatory drugs } \\
\hline Naproxen & $99.3(1.52)$ & $85.1(11.4)$ \\
\hline Ketoprofen & $91.9(6.55)$ & $51.5(22.9)$ \\
\hline Ibuprofen & $99.8(0.386)$ & $82.5(15.8)$ \\
\hline Diclofenac & $87.4(14.1)$ & $50.1(20.1)$ \\
\hline Indomethacin & $46.6(23.2)$ & $23.4(22.3)$ \\
\hline Acetaminophen & $99.6(0.299)$ & $98.4(1.72)$ \\
\hline Mefenamic acid & $74.8(20.1)$ & $29.4(32.3)$ \\
\hline Propyphenazone & $64.6(13.3)$ & $42.7(19.0)$ \\
\hline \multicolumn{3}{|l|}{ Anti-ulcer agents } \\
\hline Ranitidine & $95.0(3.74)$ & $42.2(47.0)$ \\
\hline \multicolumn{3}{|l|}{ Psychiatric drugs } \\
\hline Paroxetine & $89.7(6.69)$ & $90.6(4.74)$ \\
\hline \multicolumn{3}{|l|}{ Antiepileptic drugs } \\
\hline Carbamazepine & No elimination ${ }^{\mathrm{c}}$ & No elimination \\
\hline \multicolumn{3}{|l|}{ Antibiotics } \\
\hline Ofloxacin & $94.0(6.51)$ & $23.8(23.5)$ \\
\hline Sulfamethoxazole & $60.5(33.9)$ & $55.6(35.4)$ \\
\hline Erythromycin & $67.3(16.1)$ & $23.8(29.2)$ \\
\hline \multicolumn{3}{|l|}{ B-blockers } \\
\hline Atenolol & $65.5(36.2)$ & No elimination \\
\hline Metoprolol & $58.7(72.8)$ & No elimination \\
\hline \multicolumn{3}{|l|}{ Diuretics } \\
\hline Hydrochlorothiazide & $66.3(7.79)$ & $76.3(6.85)$ \\
\hline \multicolumn{3}{|l|}{ Hypoglycaemic agents } \\
\hline Glibenclamide & $47.3(20.1)$ & $44.5(19.1)$ \\
\hline \multicolumn{3}{|c|}{ Lipid regulator and cholesterol lowering statin drugs } \\
\hline Gemfibrozil & $89.6(23.3)$ & $38.8(16.9)$ \\
\hline Bezafibrate & $95.8(8.66)$ & $48.4(33.8)$ \\
\hline Clofibric acid & $71.8(30.9)$ & $27.7(46.9)$ \\
\hline Pravastatin & $90.8(13.2)$ & $61.8(23.6)$ \\
\hline
\end{tabular}

(44.8-82.9\% for MBR and 6.82-62.6\% for CAS) and glibenclamide $(14.8-73.7 \%$ for MBR and $11.9-79.7 \%$ for CAS).

Effluent concentrations greater than those recorded for the influent could be explained by the presence of input conjugate compounds that are transformed into the original compounds during treatment. Because these conjugates were not included in the analysis, no firm conclusion can be made about their biotransformation, especially because sampling inaccuracy can also lead to errors.

\section{Conclusion}

Several pharmaceutical products (e.g. ibuprofen, naproxen, acetaminophen, ketoprofen, diclofenac, bezafibrate, gemfi- brozil, ranitidine, ofloxacin, hydrochlorothiazide, and paroxetine) with high rates of attenuation can be expected to be completely removed from wastewater by adsorption or degradation, or a combination of both, during membrane treatment. For most of the compounds investigated MBR effluent concentrations were significantly lower than in the effluent from conventional treatment. Elimination of hydrochlorothiazide and paroxetine was slightly better in CAS treatment. Some substances (e.g. carbamazepine) were not removed by either MBR or CAS treatment. No relationship was found between the structures of target compounds and their removal during wastewater treatment, however. The range of variation of the efficiency of removal by the MBR system was small for most of the compounds; in conventional treatment greater fluctuations were observed and removal efficiency was found to be much more sensitive to changes in operating conditions (temperature, flow rate, etc).

Although membrane technology seems a promising means of removal of pharmaceutical compounds, the MBR process investigated would not completely halt discharge of micropollutants. Membrane treatment processes should be optimized by modification of the membranes (variation of the materials and reduction of molecular mass cut-off limits) and/or by modification of the treatment process (inoculation of special microorganisms). The efficiencies of diverse microbial populations in elimination of selected pharmaceuticals, and optimization of design and operating conditions of a laboratory-scale MBR will be the main objectives of our future investigations. That would provide guidelines for scale-up of a biological pilot plant and its evaluation by integration into an industrial process water-recycling system. Because of the current lack of information on the behaviour of pharmaceuticals in surface and wastewaters, however, further studies are required on the occurrence, fate, and effects of these substances in the environment.

Acknowledgements The study was supported financially by the European Union EMCO project (INCO-CT-2004-509188) and by the Spanish Ministry of Education and Science project EVITA (CTM2004-06255-CO3-01-A) and by the project CTM2005-24254-E. J.R. gratefully acknowledges the I3P Program (Itinerario integrado de inserción profesional), co-financed by CSIC (Consejo Superior de Investigaciones Científicas) and European Social Funds, for a predoctoral grant. Waters (Milford, USA) is gratefully acknowledged for providing the SPE cartridges and Merck (Darmstadt, Germany) for providing the HPLC columns. Hydrochlorothiazide and glibenclamide were kindly supplied by Dr M. Ahel (Centre for Marine and Environmental Research, Zagreb, Croatia).

\section{Appendix}

Structure and CAS numbers of the pharmaceutical products studied. 
Compound

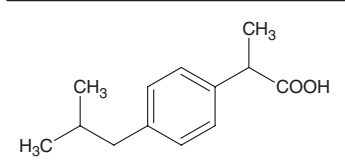

Ibuprofen<smiles>CC(O)c1cccc(C(=O)c2ccccc2)c1</smiles>

Ketoprofen<smiles>COc1ccc2cc(C(C)C(=O)O)ccc2c1</smiles>

Naproxen<smiles>O=C(O)Cc1ccccc1Nc1c(Cl)cccc1Cl</smiles>

Diclofenac

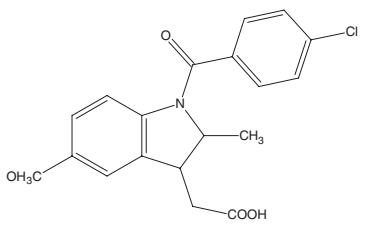

Indomethacin

HO<smiles>CC(=O)Nc1ccc(C)cc1</smiles>

Acetaminophen<smiles>CC(C)C(C)C1C(C)C(C)C(C2=CC3CCC2C3)C1C</smiles>

Propyphenazone<smiles>CCC(C)(C)OCC1CCC(C)CC1</smiles>

\section{Clofibric acid}

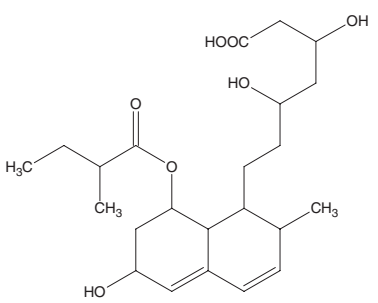

CAS number

Compound

CAS number

15687-27-1

22071-15-4

22204-53-1

15307-86-5

53-86-1

103-90-2

479-92-5

882-09-7

81093-37-0

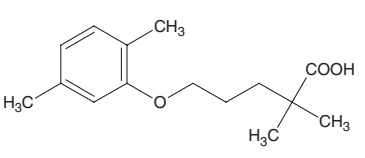

Gemfibrozil

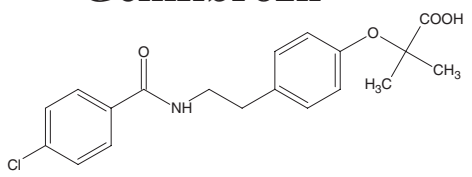

Bezafibrate

41859-67-0

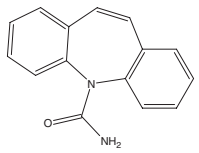

Carbamazepine

298-46-4

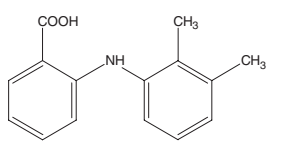

Mefenamic acid

61-68-7

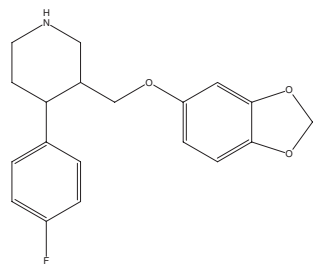

Paroxetine

110429-35-1

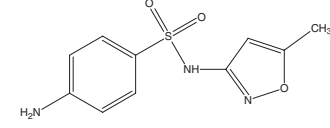

Sulfamethoxazole

723-46-6

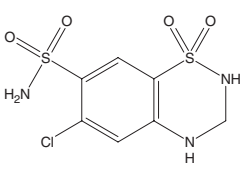

Hydrochlorothiazide

58-93-5<smiles>CCCc1ccc(OCC(O)CCC(C)C)cc1</smiles>

Metoprolol

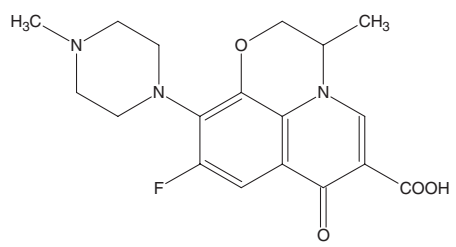

37350-58-6

82419-36-1 
Pravastatin

Continuation of Appendix<smiles>CC(C)CCC(O)COc1ccc(CC(N)=O)cc1</smiles>

Atenolol

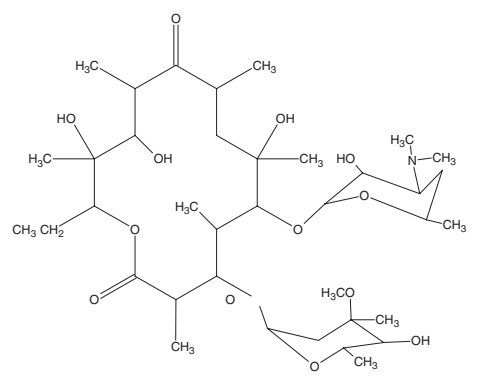

Erythromycin

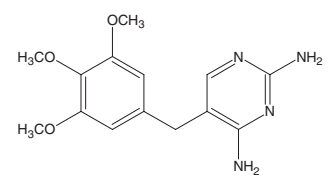

Trimethoprim<smiles>CC(CNC(C)(C)C)COc1ccc2ccccc2c1</smiles>

Propranolol

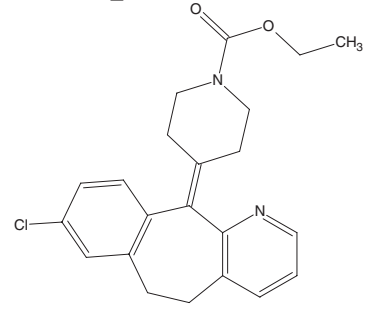

Loratidine

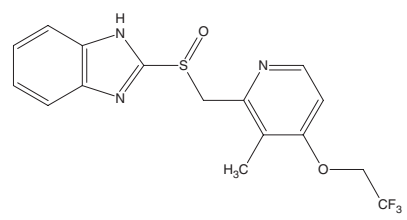

Lansoprazole

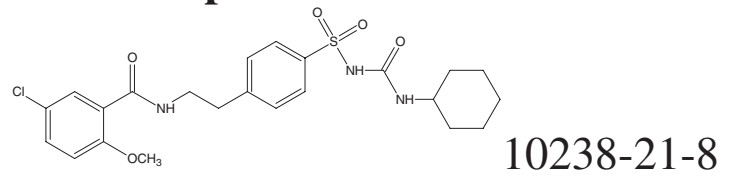

Glibenclamide
29122-68-7

$114-07-8$

738-70-5

3506-09-0

79794-75-5

103577-45-3

10238-21-8

\section{Ofloxacin}

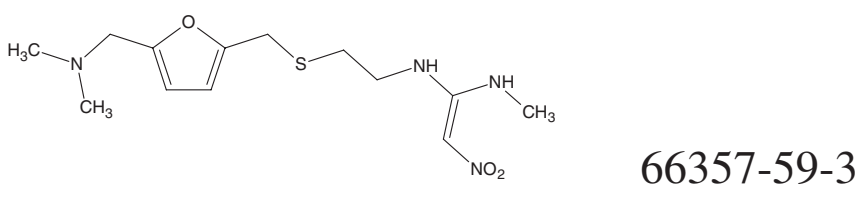

Ranitidine

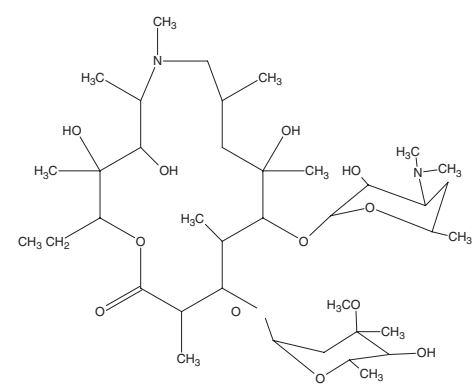

\section{Azithromycin}

117772-70-0

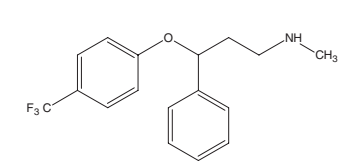

Fluoxetine

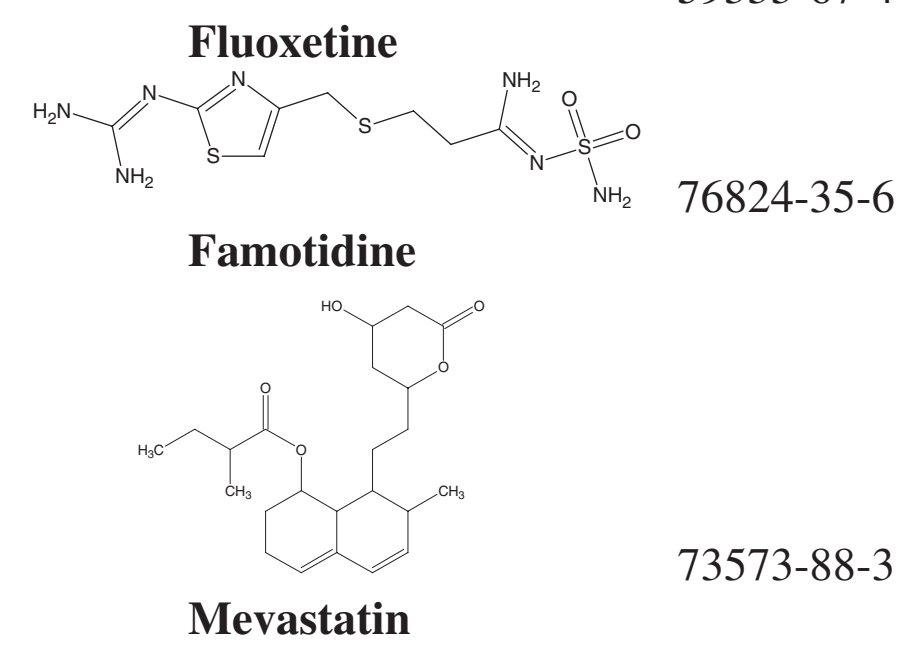

Famotidine

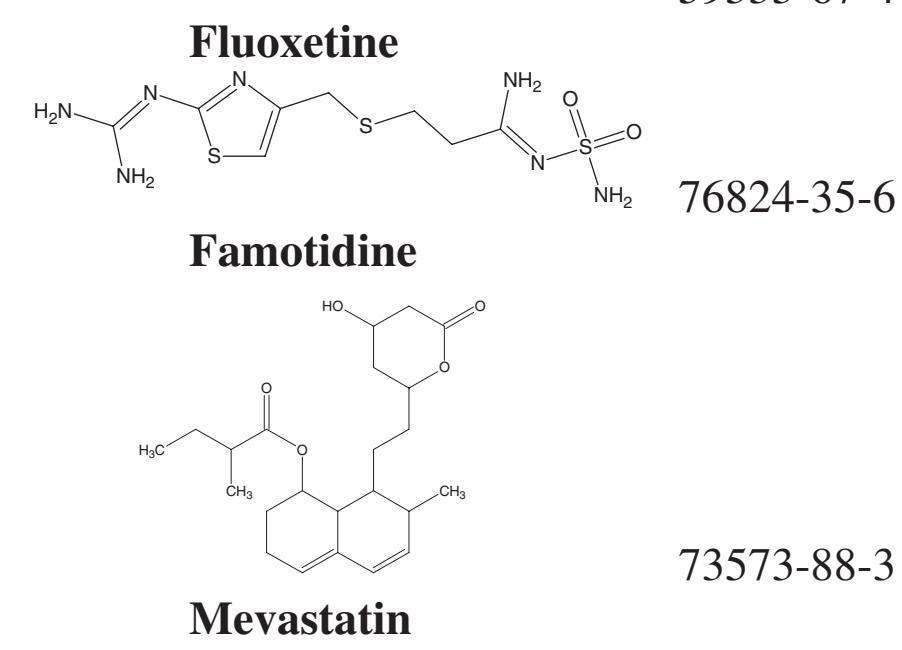

Mevastatin

73573-88-3

59333-67-4

959-24-0

Sotalol 


\section{References}

1. Halling-Sørensen B, Nors Nielsen S, Lanzky PF, Ingerslev F, Holten Lutzhøft HC, Jørgensen SE (1998) Chemosphere 36:357393

2. Clara M, Kreuzinger N, Strenn B, Gans O, Kroiss H (2005) Water Res 39:97-106

3. Vieno NM, Tuhkanen T, Kronberg L (2005) Environ Sci Technol 39:8220-8226

4. Petrovic M, Gonzalez S, Barcelo D (2003) Trends Anal Chem 22:685-696

5. Kolpin DW, Furlong ET, Meyer MT, Thurman EM, Zaugg SD, Barber LB, Buxton HT (2002) Environ Sci Technol 36:12021211

6. Buser HR, Poiger T, Muller MD (1999) Environ Sci Technol 33:2529-2535

7. Heberer T (2002) Toxicol Lett 131:5-17

8. Ternes TA (1998) Water Res 32:3245-3260

9. Metcalfe CD, Koenig BG, Bennie DT, Servos M, Ternes TA, Hirsch R (2003) Environ Toxicol Chem 22:2872-2880

10. Castiglioni S, Bagnati R, Fanelli R, Pomati F, Calamari D, Zuccato E (2006) Environ Sci Technol 40:357-363

11. Joss A, Keller E, Alder AC, Göbel A, McArdell CS, Ternes T, Siegrist H (2005) Water Res 39:3139-3152
12. Giger W, Alder AC, Golet EM, Kohler HPE, McArdell CS, Molnar E, Siegrist H, Suter MJF (2003) Chimia 57:485-491

13. Jjemba PK (2006) Ecotoxicol Environ Saf 63:113-130

14. Clara M, Strenn B, Kreuzinger N, Kroiss H, Gans O, Martinez E (2005) Water Res 39:4797-4807

15. Quintana JB, Weiss S, Reemtsma T (2005) Water Res 39:26542664

16. Joss A, Zabczynski S, Gobel A, Hoffmann B, Loffler D, McArdell CS, Ternes TA, Thomsen A, Siegrist H (2006) Water Res 40:1686-1696

17. Urase T, Kagawa C, Kikuta T (2005) Desalination 178:107-113

18. Gross M, Petrovic M, Barcelo D (2006) Talanta, in press

19. Xing CH, Tardieu E, Qian Y, Wen XH (2000) J Membr Sci 177:73-82

20. Cicek N, Wiennen H, Suidan MT, Wrenn BE, Urbain V, Manem J (1998) Water Res 32:1553-1563

21. http://www.syrres.com/

22. http://poseidon.bafg.de/

23. Strenn B, Clara M, Gans O, Kreuzinger N (2004) Water Sci Technol 50:269-276

24. Clara M, Strenn B, Kreuzinger N (2004) Water Res 38:947-954

25. Drillia P, Dokianakis SN, Fountoulakis MS, Kornaros M, Stamatelatou K, Lyberatos G (2005) J Hazard Mater 122:259-265

26. Gobel AMCS, Suter MJF, Giger W (2004) Anal Chem 76:47564764 